\title{
Paleobiografía del « Pobrecito Holgazán » Sebastián de Miñano
}

\section{Alberto Gil Novales}

\section{(2) OpenEdition \\ 1 Journals}

Édition électronique

URL : https://journals.openedition.org/ahrf/1751

DOI : 10.4000/ahrf.1751

ISSN : 1952-403X

\section{Éditeur :}

Armand Colin, Société des études robespierristes

\section{Édition imprimée}

Date de publication : 1 juin 2004

Pagination : 240-241

ISSN : 0003-4436

\section{Référence électronique}

Alberto Gil Novales, "Paleobiografía del « Pobrecito Holgazán » Sebastián de Miñano », Annales historiques de la Révolution française [En ligne], 336 | avril-juin 2004, mis en ligne le 20 février 2006 consulté le 24 avril 2022. URL : http://journals.openedition.org/ahrf/1751 ; DOI : https://doi.org/ 10.4000/ahrf.1751

Ce document a été généré automatiquement le 24 avril 2022.

Tous droits réservés 


\title{
Paleobiografía del « Pobrecito Holgazán » Sebastián de Miñano
}

\author{
Alberto Gil Novales
}

\section{RÉFÉRENCE}

Claude Morange, Paleobiografía del « Pobrecito Holgazán » Sebastián de Miñano, Salamanque, Ediciones Universidad de Salamanca, 2002, 402 p., ISBN 84-7800-775-X, 27 $€$.

1 Voici la première partie de la biographie de Sebastián de Miñano, à laquelle Claude Morange a travaillé pendant de longues années. Comme l'indique le titre, l'ouvrage concerne la fraction la plus ancienne de la biographie, c'est-à-dire les quarante premières années de la vie de l'auteur du Pobrecito Holgazán, personnage littéraire délibérement confondu avec son créateur. Miñano est devenu fameux en Espagne par la publication, en 1820, des Lamentos políticos de un Pobrecito Holbazán. Pour connaître les raisons de ce succès, il faut envisager la vie antérieure de l'écrivain.

2 Morange a été fidèle à sa mission, a été rigoureux dans son raisonnement, où il a mis la richesse et la précision de ses connaisances. Dans la préface même du livre, l'auteur fait sienne une sentence de Pío Baroja dans Juan Van Halen: « Mon intention a été de faire un livre documenté; quelqu'un d'autre pourra écrire un livre éloquent ».

3 Au travers de treize chapitres et un épilogue, le livre nous offre le parcours vital de son sujet: les origines de la famille, la vie d'Andrés Miñano, le père, sur lequel nous pouvons trouver ici des pages admirables; ensuite les études, « au fond la Révolution française », Godoy et les Lumières, le Cardinal Infant Luis María de Borbón, l'Inquisition. Miñano laisse la toge pour la soutane non par vocation, mais parce qu'on a besoin de quelque chose pour vivre. L'auteur nous introduit dans la complexité de la vie ecclésiastique et aussi culturelle, surtoût de Séville, en nous exposant un problème de grandes résonnances, celui de la légalité du théatre. 
4 La toile des événements nous donne la Guerre de l'Indépendance, l'insurrection de Séville et la formation de sa Junte, et un peu après celle-là de la Junte Centrale. Il y a en 1809 un intense débat idéologique. Le pouvoir de Soult à Séville n’a pas de limites: Miñano a commencé par résister, ensuite il s'est soumis, finalement il va collaborer sans nuances. C'est très facile à dire qu'il est devenu un Afrancesado, mais la question importante est ici de savoir comment cela s'est fait, avec quelle moisson de sacrifices et de rénonciations. Nous trouvons ici une exposition formidable du contenu, et de ses limitations, de ce que nous appellons Afrancesamiento.

5 Après Miñano va partir en exil, où il va faire la connaissance de Agustina Montiel de Ochoa, laquelle va devenir sa femme. Toujours il y a ici une exposition de la vie inmédiate, mais aussi des arrières-plans, les conditions de la vie en France, et les vains espoirs d'arriver à une réconciliation nationale. Miñano va faire aussi la connaissance du publiciste León Amarita, et va devenir un des collaborateurs de la Gazeta de Bayona. Ensuite la purification et le retour en Espagne. L'épilogue s'occupe de la relation générationnelle de Miñano avec d'autres Afrancesados, pour saisir mieux le contenu historique du mot et aussi pour donner un sens plus précis au concept même de génération.

Voilà à grands traits le résumé du livre. Mais je sais bien qu'il y a des choses que je n'ai pas même mentionnées, des choses importantes pour le grand public, mais aussi pour les spécialistes. Dejà on a parlé ici de quelques grands thèmes, toujours repensés par l'auteur à travers le prisme de ses créatures: la Révolution française, Godoy, les Lumières, Séville, la lutte pour et contre le théatre, la Guerre de l'Indépendance et l'Afrancesamiento. Il y a d'autres sujets sur lesquels Morange donne des précisions; sa consultation devient nécessaire même pour les spécialistes. Je pense à l'histoire de la Presse ou de la Franc-maçonnerie, et aussi à la grande quantité de personnages et de petits personnages identifiés par l'auteur dans un moment concret.

Il faut le dire, cette Paleobiografía est un grand livre, et en plus l'édition est excellente, sans luxe et aussi sans misères, avec cette sobriété qui devient un trait constitutif et de l'auteur et de l'éditeur. Le livre a aussi un très utile index ononomastique. Je suis partisan d'y mettre les prénoms complets, seule possibilité de séparer José de Joaquín. Aussi, chez les historiens espagnols il y a une grande tendance à ne pas répéter l'année de laquelle on parle, seulement le jour et le mois. Mais par commodité, et par courtoisie envers le lecteur, il faut n'avoir pas peur d'écrire deux ou trois fois l'année. Cela sera mieux.

8 Je veux finir par féliciter l'auteur et les Éditions de l'Université de Salamanque pour avoir écrit et publié cet livre. 